\title{
Knowledge and attitude of maternity nurses regarding perinatal bereavement care
}

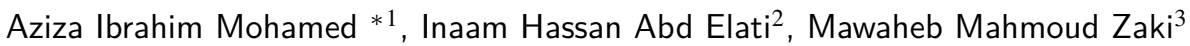 \\ ${ }^{1}$ Maternal and Newborn Health Nursing, Benha University, Banha, Egypt \\ ${ }^{2}$ Maternal and Newborn Health Nursing, Port-SaidUniversity, Port Said, Egypt \\ ${ }^{3}$ Psychiatric and Mental Health Nursing, Benha University, Banha, Egypt
}

Received: December 2, 2014

DOI: $10.5430 /$ jnep.v5n2p136
Accepted: December 21, 2014 Online Published: January 13, 2015

URL: http://dx.doi.org/10.5430/jnep.v5n2p136

\begin{abstract}
Background: Parents whose infants had died are in need for especial care and support, these needs are difficult and stressful. This study was aimed to evaluate knowledge and attitude of maternity nurses regarding perinatal bereavement care.

Method: A convenience sample including 50 maternity nurses were participated in the current study. Design: A descriptive study design was utilized to conduct the current study. Tools: Two tools were used for data collection, an interview schedule and attitude likerate scale.

Results: The current study findings revealed that, nurses had inadequate level of knowledge, positive and highly positive attitude regarding perinatal bereavement care were presented in $(26 \%, \& 64 \%)$ of nurses respectively. Nurses reside in rural areas, had personal grieving experiences and those had past experience in handling grieving parents had a highly positive attitude toward perinatal bereavement care.

Conclusion: This study finding showed that, bereavement counseling education and preceptorship supervision are recommended to reduce this stressful experience, increase the confidence and expertise of nurses, and lead to increased quality of care for bereaved parents.
\end{abstract}

Key Words: Perinatal bereavement care, Nurses' attitude, Nurses' knowledge

\section{Introduction}

Being a parent is an important developmental milestone that is in prospect by most males and females in our Egyptian society. Perinatal bereavement is the non-voluntary end of pregnancy from the beginning of conception, during pregnancy period, or up to 28 days of the newborn's life. Also, perinatal bereavement includes; spontaneous abortion, ectopic pregnancy, stillbirth, late-pregnancy loss, and newborn death. $^{[1]}$ Bereavement is overwhelmingly been misunderstood, stigmatized and failed to receive adequate confession. ${ }^{[2]}$
The partners' response to perinatal bereavement is individually differs, but is commonly very vehement. Men and women grieve differently, which can sometimes cause conflict between partners. Women usually tend to grieve more openly than men; also they may have physical changes. Grieving may continue to a few weeks, several months, or often longer than a year. The grief and distress experienced by parents has been documented across qualitative and quantitative studies. ${ }^{[1,3-5]}$

Bereavement care is recommended to be immediately after perinatal bereavement because it can provide tremen-

*Correspondence: Aziza Ibrahim Mohamed; Email: aziza.hassan@fnur.bu.edu.eg; Address: Maternal and Newborn Health Nursing, Benha University, Banha, Egypt. 
dous benefits, validating a woman's response to the loss and providing her a great opportunity to express her feelings. ${ }^{[6]}$ Perinatal death is still marginalized in medical researches and sophisticated investigations of parents' experiences has emphasized the importance of events and care provided at this sensitive time, and everyone involved had only once chance to get it right. ${ }^{[7]}$

Grieving parents recognize the full worth to health care professionals when they conveying respect for their particular needs and avow to the significance of their loss, parents persist to report emotional, spiritual, or practical needs that unfulfilled in hospitals, in its turn, which leads to increases family distress during and after a newborn's death, ${ }^{[2]}$ they values are empathetic, humble, consistent, and honest communication during their crisis. ${ }^{[5]}$

Maternity nurses must have a powerful influence on how parents experience and cope with perinatal bereavement. ${ }^{[8]}$ Many nurses grieve when patients stop living; however, nurses' grief is not often acknowledged or discussed. Also, little attention is given to make nurses get ready for this experience in nursing curriculum and in orientations to health care organizations. ${ }^{[9]}$ The purpose of this research was to evaluate knowledge, and attitude of maternity nurses regarding perinatal bereavement care.

\subsection{Significance of the study}

Maternity nurses are often relied on to care for bereaved parents and families affected by perinatal bereavement traumatic events, which are stressful for all involved, ${ }^{[10]}$ and are expected to interact with the bereaved in a supportive manner, regardless whether they feel adequately prepared or disposed to do. ${ }^{[11]}$ So, the present study is intended to assess knowledge and attitude of maternity nurse regarding perinatal bereavement care.

\subsection{Aim of the study}

The aim of the present study was to evaluate knowledge, and attitude of maternity nurses regarding perinatal bereavement care.

\subsection{Research question}

- What is the level of maternity nurses' knowledge regarding perinatal bereavement care?

- What is the attitude of maternity nurses regarding perinatal bereavement care?

- Is there is a relation between the studied nurses' personnel characteristics and their knowledge and attitude regarding perinatal bereavement?

\section{Methodology}

\subsection{Design}

A descriptive study design was utilized to conduct the current study.

\subsection{Setting}

The present study conducted at labor, antepartum, postpartum, and gynecologic units affiliated to obstetric and gynecologic department, Benha University Hospital.

\subsection{Subjects}

A convenience sample of a total fifty maternity nurses working in obstetric and gynecology medicine department at Benha University hospital that met the following inclusion criteria were recruited at the study.

\subsection{Inclusion criteria}

Nurse who had at least one year of experience at obstetric and gynecologic department was involved in the current study.

\subsection{Tools of data collection}

Two tools were utilized for data collection.

Tool 1: An interviewing schedule questionnaire: A questionnaire sheet was developed by the researcher after reviewing related literature, it was consisted of two parts, the first part was concerned with personnel characteristics data(i.e. age, education level, etc.), past experiences (i.e. personal grieving, handling grieving clients, and years of work in the obstetrics and gynecologic department), and training programs (i.e. bereavement care), while the second part deals with knowledge regarding bereavement care; it was consisted of (9) questions on concepts of perinatal bereavement and bereavement care. Each correct answer were scored (1), and incorrect were scored (0). Sum the score for each question, total score was calculated as $60.0 \%$ or more was considered adequate and less than $60.0 \%$ was inadequate.

Tool 2: A likert scale was utilized to evaluate maternity nurses attitude regarding perinatal bereavement care (modified version): It was adopted from Chan et al. (2004), and it was modified by the researcher to measure nurses' attitudes towards bereavement care using a Likert-type, 3 point scale ranging from " $1=$ disagree to $2=$ uncertain, and 3 = agree". It was consisted of two parts; first part concerning with nurses attitude regarding importance of perinatal bereavement; it includes eight statements, while the second part measuring nurses attitude regarding factors affecting perinatal bereavement care; it also was included eight statements. Total attitude score was assigned as; highly positive attitude $(>75.0 \%)$, positive attitude $(50.0 \%-75.0 \%)$, and negative attitude $(<50.0 \%)$. 


\subsection{Field of work}

Written approvals were obtained from Benha University Hospital and research committee at Benha University. The purpose of the study was explained to each participant, assured confidentiality and informed about their right to withdraw from the study at any time without giving any reason. A written consent was obtained from each participant. The researcher was explained the items of tool to each participant, and the questionnaire was filled in by the participants over a time of 30 minutes.Data was collected over a period from January, 2014 to March, 2014.

\subsection{Validity and reliability}

Tool validity test was done through five panels of expertise in the field of maternity and psychiatric nursing to test the content validity. Modification was carried out according to the panel judgment on clarity of sentences and appropriateness of content. The internal consistency of likert scale has been tested using Cronbach's alpha coefficient. Cronbach'salphas were $(0.964, \& 0.875)$ for attitude of nurses regarding importance of perinatal bereavement and factors affecting perinatal bereavement care respectively.

\subsection{Pilot study}

A pilot research was carried out on $10.0 \%$ of the total sample to check clarity and feasibility of tool and estimated the time needed for data collection. All nurses who participated at research pilot study were excluded from the research sample.

\subsection{Ethical considerations}

The purpose of the study was explained to each nurse and a written informed consent was obtained from 50 enrolled nurses after explaining the purpose of the study, assuring confidentiality and their right to withdraw from the study at any time without any reason.

\subsection{Research strength}

The responsible authorities and participants were cooperated with the researcher at the time of the present study.

\subsection{Statistical analysis}

Data entry and statistical analysis were performed using personal computer software, the statistical package for social sciences (SPSS), version 14. Suitable descriptive statistics were used such as; frequency, percentage, median, mean and standard deviation. Chi-square test was used to detect the relation between the variables. In addition, correlation coefficient $(r)$ test was used to estimate the closeness association between variables. For all the tests, statistical significance was considered at $p$-value $<.05$.

\section{Result}

Table 1 illustrates general characteristics of participants, the table shows that, the age of nurses under study was ranged between (20-45 yrs) with a mean of $(29.60 \pm 6.80)$, the minority of them was highly educated $(14.0 \%)$. The same table manifest that, all nurses had not received any educational programs about bereavement care.

Table 1: Frequency of the studied participants regarding their personnel characteristics

\begin{tabular}{|c|c|c|}
\hline Variables & Frequency & $\%$ \\
\hline \multicolumn{3}{|l|}{ Age in years } \\
\hline $20-$ & 27 & 54.0 \\
\hline $30-$ & 17 & 34.0 \\
\hline $40-45$ & 6 & 12.0 \\
\hline Mean \pm SD & $29.60 \pm 6.80$ & \\
\hline \multicolumn{3}{|l|}{ Educational qualification } \\
\hline Secondary nursing education & 29 & 58.0 \\
\hline Technical nursing education & 14 & 28.0 \\
\hline Bacculare of nursing education & 7 & 14.0 \\
\hline \multicolumn{3}{|l|}{ Years of experience } \\
\hline$<5$ years & 23 & 46.0 \\
\hline $5-10$ & 20 & 40.0 \\
\hline$>10$ years & 7 & 14.0 \\
\hline Mean \pm SD & $11.5 \pm 7.3$ & \\
\hline \multicolumn{3}{|l|}{ Marital status } \\
\hline Single & 7 & 14.0 \\
\hline Married & 41 & 82.0 \\
\hline Widow & 2 & 4.0 \\
\hline \multicolumn{3}{|l|}{ Residence } \\
\hline Urban & 41 & 82.0 \\
\hline Rural & 9 & 18.0 \\
\hline \multicolumn{3}{|l|}{ Personal grieving experiences } \\
\hline Yes & 11 & 22.0 \\
\hline No & 39 & 78.0 \\
\hline \multicolumn{3}{|l|}{$\begin{array}{l}\text { Taken training/courses related to } \\
\text { bereavement care }\end{array}$} \\
\hline Yes & 0 & .0 \\
\hline No & 50 & 100.0 \\
\hline \multicolumn{3}{|l|}{$\begin{array}{l}\text { Past experience in handling grieving } \\
\text { parents }\end{array}$} \\
\hline Yes & 17 & 34.0 \\
\hline No & 33 & 66.0 \\
\hline
\end{tabular}

Table 2 describes the level of nurses' knowledge about perinatal bereavement regarding; definition, factors that affect parents experience and cope with their loss, basics skills of bereavement counseling, essential steps to counseling bereaved parent and risks for complicate grief. The same table noticed that, the majority of nurses had inadequate knowledge about perinatal bereavement (82.0\%).

Table 3 shows attitude of nurses regarding importance of perinatal bereavement as agree, uncertain or disagree. Approximately two thirds $(72 \%, 74 \%)$ of them agreed that bereaved parent's feelings and needs should be respected, all those involved in the care of bereaved parents should be well-informed and, It is normal for women to experience sadness for six weeks following perinatal loss respectively. 
Table 2: Distribution of the studied participant according to their knowledge level about perinatal bereavement $(\mathrm{n}=50)$

\begin{tabular}{|c|c|c|c|c|}
\hline \multirow{2}{*}{ Item } & \multicolumn{2}{|c|}{ Inadequate } & \multicolumn{2}{|c|}{ Adequate } \\
\hline & No & $\%$ & No & $\%$ \\
\hline Meaning of bereavement care. & 33 & 66.0 & 17 & 34.0 \\
\hline Factors that might have an impact on how different parents experience and cope with their loss & 35 & 70.0 & 15 & 30.0 \\
\hline Basics skills of bereavement counseling. & 29 & 58.0 & 21 & 42.0 \\
\hline Essential steps to counseling bereaved parent. & 37 & 74.0 & 13 & 26.0 \\
\hline Risks for complicate grief & 33 & 66.0 & 17 & 34.0 \\
\hline Effect of perinatal bereavement on the couple relationship & 38 & 76.0 & 12 & 24.0 \\
\hline Psychological effect of perinatal bereavement on mothers. & 35 & 70.0 & 15 & 30.0 \\
\hline Psychological effect of perinatal bereavement on fathers & 42 & 84.0 & 8 & 16.0 \\
\hline Medical needs after perinatal bereavement & 37 & 74.0 & 13 & 26.0 \\
\hline Total score & 41 & 82.0 & 9 & 18.0 \\
\hline
\end{tabular}

Table 3: Attitude of the studied participants regarding importance of perinatal bereavement $(n=50)$

\begin{tabular}{|c|c|c|c|c|c|c|}
\hline \multirow{2}{*}{ Item } & \multicolumn{2}{|c|}{ Disagree } & \multicolumn{2}{|c|}{ Uncertain } & \multicolumn{2}{|c|}{ Agree } \\
\hline & No & $\%$ & No & $\%$ & No & $\%$ \\
\hline The grief caring program provides psychological support to the bereaved parents. & 0 & .0 & 26 & 52.0 & 24 & 48.0 \\
\hline Bereaved parent's feelings and needs should be respected & 3 & 6.0 & 11 & 22.0 & 36 & 72.0 \\
\hline communication with parents in a clear, sensitive and honest manner & 4 & 8.0 & 12 & 24.0 & 34 & 68.0 \\
\hline Bereaved parents should be given time to grieve. & 7 & 14.0 & 12 & 24.0 & 31 & 62.0 \\
\hline All those involved in the care of bereaved parents should be well-informed. & 1 & 2.0 & 12 & 24.0 & 37 & 74.0 \\
\hline $\begin{array}{l}\text { Bereaved families require professional follow up in order to cope with the experience } \\
\text { of perinatal loss. }\end{array}$ & 1 & 2.0 & 15 & 30.0 & 34 & 68.0 \\
\hline It is normal for women to experience sadness for six weeks following perinatal loss. & 0 & .0 & 13 & 26.0 & 37 & 74.0 \\
\hline Grief felt after early pregnancy loss can be equal to grief felt with any other loss. & 5 & 10.0 & 18 & 36.0 & 27 & 54.0 \\
\hline
\end{tabular}

Table 4 shows attitude of nurses regarding factors affecting care of perinatal bereavement. The majority of nurses agreed to join a training program on bereavement care (90.0\%). Approximately two thirds of them agreed that all maternity care staff should participate in bereavement care, share experiences with colleagues and working as a team
(74.0\%), and $68.0 \%$ of them agreed that, the unit should have a clear policy for the management of bereavement. Moreover this table indicates that $10.0 \%$ of nurses had a negative attitude towards bereavement care, $26.0 \%$ of them had positive attitude, compared with $64.0 \%$ of them had a highly positive attitude.

Table 4: Attitude of the studied participants regarding factors affecting care of perinatal bereavement $(n=50)$

\begin{tabular}{|c|c|c|c|c|c|c|}
\hline \multirow{2}{*}{ Item } & \multicolumn{2}{|c|}{ Disagree } & \multicolumn{2}{|c|}{ Uncertain } & \multicolumn{2}{|c|}{ Agree } \\
\hline & No & $\%$ & No & $\%$ & No & $\%$ \\
\hline The maternity care unit should have a clear policy for the management of perinatal bereavement & 2 & 4.0 & 17 & 34.0 & 31 & 62.0 \\
\hline All maternity care staff involved should understand the policy. & 6 & 12.0 & 15 & 30.0 & 29 & 58.0 \\
\hline All maternity care staff should join a training program on bereavement care. & 3 & 6.0 & 2 & 4.0 & 45 & 90.0 \\
\hline All maternity care staff should participate in bereavement care & 3 & 6.0 & 7 & 14.0 & 40 & 80.0 \\
\hline $\begin{array}{l}\text { All maternity care staff should share experiences with colleagues and working as a team while } \\
\text { caring bereaved parents. }\end{array}$ & 1 & 2.0 & 11 & 22.0 & 38 & 76.0 \\
\hline All maternity care staff should seek support when experiencing 'burnout' & 2 & 4.0 & 16 & 32.0 & 32 & 64.0 \\
\hline \multirow[t]{2}{*}{ Proper training should provide for all staff Participate in bereavement care } & 1 & 2.0 & 13 & 26.0 & 36 & 72.0 \\
\hline & \multicolumn{2}{|c|}{ Negative } & \multicolumn{2}{|c|}{ Positive } & \multicolumn{2}{|c|}{ High positive } \\
\hline \multirow[t]{2}{*}{ Total attitude score } & No & $\%$ & No & $\%$ & No & $\%$ \\
\hline & 5 & 10 & 13 & 26 & 32 & 64 \\
\hline
\end{tabular}

Table 5 shows the relation between total knowledge score and nurses' personnel characteristics. It was observed that, there were a statistically significance relation between age, educational level and knowledge level whereas $(p<.05)$. Published by Sciedu Press
Table 6 illustrates that, there were a highly statistically significance relation between residence, personal grieving experience, past experience in handling grieving parents and nurses' attitude toward perinatal bereavement $(p<.000)$. 
Table 5: Relation between total knowledge score and personnel characteristics among studied participants $(\mathrm{n}=50)$

\begin{tabular}{|c|c|c|c|c|c|c|}
\hline \multirow{3}{*}{ Variables } & \multicolumn{4}{|c|}{ Total knowledge score } & \multirow{3}{*}{$\chi^{2}$} & \multirow{3}{*}{$p$} \\
\hline & \multicolumn{2}{|c|}{ Inadequate $N=41$} & \multicolumn{2}{|c|}{ Adequate $\mathbf{N}=9$} & & \\
\hline & No & $\%$ & No & $\%$ & & \\
\hline \multicolumn{7}{|l|}{ Age in years } \\
\hline $20-$ & 19 & 46.3 & 8 & 88.9 & \multirow{3}{*}{5.48} & \multirow{3}{*}{$<.05^{*}$} \\
\hline $30-$ & 16 & 39.0 & 1 & 11.1 & & \\
\hline $40-45$ & 6 & 14.6 & 0 & .0 & & \\
\hline \multicolumn{7}{|l|}{ Educational qualification } \\
\hline Secondary nursing education & 23 & 56.1 & 6 & 66.7 & \multirow{3}{*}{6.14} & \multirow{3}{*}{$<.05^{*}$} \\
\hline Technical nursing education & 14 & 34.1 & 0 & 0.0 & & \\
\hline Bacculare of nursing education & 4 & 9.8 & 3 & 33.3 & & \\
\hline \multicolumn{7}{|l|}{ Years of experience } \\
\hline$<5$ years & 17 & 41.5 & 6 & 66.7 & \multirow{3}{*}{2.67} & \multirow{3}{*}{$>.05$} \\
\hline $5-10$ & 17 & 41.5 & 3 & 33.3 & & \\
\hline$>10$ years & 7 & 17.1 & 0 & 0.0 & & \\
\hline \multicolumn{7}{|l|}{ Marital status } \\
\hline Single & 5 & 12.2 & 2 & 22.2 & \multirow{3}{*}{0.993} & \multirow{3}{*}{$>.05$} \\
\hline Married & 34 & 82.9 & 7 & 77.8 & & \\
\hline Widow & 2 & 4.9 & 0 & .0 & & \\
\hline \multicolumn{7}{|l|}{ Residence } \\
\hline Urban & 35 & 85.4 & 6 & 66.7 & \multirow[t]{2}{*}{1.74} & \multirow[t]{2}{*}{$>.05$} \\
\hline Rural & 6 & 14.6 & 3 & 33.3 & & \\
\hline \multicolumn{7}{|l|}{ Personal grieving experiences } \\
\hline No & 33 & 80.5 & 6 & 66.7 & \multirow[t]{2}{*}{0.822} & \multirow[t]{2}{*}{$>.05$} \\
\hline Yes & 8 & 19.5 & 3 & 33.3 & & \\
\hline \multicolumn{7}{|c|}{ Past experience in handling grieving parents } \\
\hline No & 27 & 65.9 & 6 & 66.7 & \multirow[t]{2}{*}{0.002} & \multirow[t]{2}{*}{$>.05$} \\
\hline Yes & 14 & 34.1 & 3 & 33.3 & & \\
\hline
\end{tabular}

* statistical significant difference

Table 6: Relation between total attitude score and personnel characteristics among studied participants $(\mathrm{n}=50)$

\begin{tabular}{|c|c|c|c|c|c|c|c|c|}
\hline \multirow{3}{*}{ Variables } & \multicolumn{6}{|c|}{ Total attitude score } & \multirow{3}{*}{$\chi^{2}$} & \multirow{3}{*}{$p$} \\
\hline & \multicolumn{2}{|c|}{ Negative $N=5$} & \multicolumn{2}{|c|}{ Positive $\mathrm{N}=13$} & \multicolumn{2}{|c|}{ Highly positive $\mathrm{N}=32$} & & \\
\hline & No & $\%$ & No & $\%$ & No & $\%$ & & \\
\hline \multicolumn{9}{|l|}{ Age in years } \\
\hline $20-$ & 2 & 40.0 & 6 & 46.2 & 19 & 59.4 & \multirow{3}{*}{1.27} & \multirow{3}{*}{$>.05$} \\
\hline $30-$ & 2 & 40.0 & 5 & 38.5 & 10 & 31.3 & & \\
\hline $40-45$ & 1 & 20.0 & 2 & 15.4 & 3 & 9.4 & & \\
\hline \multicolumn{9}{|l|}{ Educational qualification } \\
\hline Secondary nursing education & 2 & 40.0 & 9 & 69.2 & 18 & 56.3 & \multirow{3}{*}{1.89} & \multirow{3}{*}{$>.05$} \\
\hline Technical nursing education & 1 & 20.0 & 2 & 15.4 & 4 & 12.5 & & \\
\hline Bacculare of nursing education & 2 & 40.0 & 2 & 15.4 & 10 & 31.3 & & \\
\hline \multicolumn{9}{|l|}{ Years of experience } \\
\hline$<5$ years & 1 & 20.0 & 7 & 53.8 & 15 & 46.9 & \multirow{3}{*}{1.89} & \multirow{3}{*}{$>.05$} \\
\hline $5-10$ & 3 & 60.0 & 4 & 30.8 & 13 & 40.6 & & \\
\hline$>10$ years & 1 & 20.0 & 2 & 15.4 & 4 & 12.5 & & \\
\hline \multicolumn{9}{|l|}{ Marital status } \\
\hline Single & 1 & 20.0 & 1 & 7.7 & 5 & 15.6 & \multirow{3}{*}{1.91} & \multirow{3}{*}{$>.05$} \\
\hline Married & 4 & 80.0 & 12 & 92.3 & 25 & 78.1 & & \\
\hline Widow & 0 & .0 & 0 & .0 & 2 & 6.3 & & \\
\hline \multicolumn{9}{|l|}{ Residence } \\
\hline Urban & 5 & 100.0 & 13 & 100.0 & 23 & 71.9 & \multirow[t]{2}{*}{6.17} & \multirow[t]{2}{*}{$<.05^{*}$} \\
\hline Rural & 0 & .0 & 0 & .0 & 9 & 28.1 & & \\
\hline \multicolumn{9}{|l|}{ Personal grieving experiences } \\
\hline Yes & 0 & .0 & 0 & .0 & 11 & 34.4 & \multirow[t]{2}{*}{7.93} & \multirow[t]{2}{*}{$<.05^{*}$} \\
\hline No & 5 & 100.0 & 13 & 100.0 & 21 & 65.6 & & \\
\hline \multicolumn{9}{|c|}{ Past experience in handling grieving parents } \\
\hline Yes & 0 & .0 & 0 & .0 & 17 & 53.1 & \multirow[t]{2}{*}{14.48} & \multirow[t]{2}{*}{$<.001^{* * *}$} \\
\hline No & 5 & 100.0 & 13 & 100.0 & 15 & 46.9 & & \\
\hline
\end{tabular}

* statistical significant difference; ** highly statistical significant difference 
Table 7 indicates that there was a highly statistical significant correlation between maternity nurses' knowledge and attitude regarding perinatal bereavement.

Table 7: Correlation between knowledge and attitude of studied participants

\begin{tabular}{llc}
\hline Attitude & $\boldsymbol{r}$ & $\boldsymbol{p}$ \\
\hline Knowledge & .680 & $.000 * *$ \\
\hline$* *$ Correlation is significant at the 0.01 level (2-tailed).
\end{tabular}

\section{Discussion}

The aim of present study was to evaluate knowledge and attitude of maternity nurses regarding perinatal bereavement care. This aim was highly significantly achieved through the present study findings. The current study findings were observed that, $82.0 \%$ of nurses had inadequate knowledge about perinatal bereavement care. These findings are in the same line with the study conducted byRaddi, Samson, and Kharde $^{[12]}$ to assess knowledge and attitude of nurses regarding bereavement; they were noted that $40.0 \%$ of nurses had poor knowledge.

In the current study lack of educational programs about bereavement care leads to poor knowledge level. Moreover $90.0 \%$ of nurses agreed to attach bereavement training programme.These findings are in agreement with Zhang and Lane ${ }^{[13]}$ who pointed out that, nurses need to be knowledgeable about end of life and bereavement issues to provide quality care.Also, these findings are in accordance with (Eckerd 2009; Chan et al., 2007; Chan, Chan and Day $2004)^{[14-16]}$ who were added that, small numbers of nurses and midwives report having had bereavement care training.

In addition Montero et al. (2011) stated that, specific training was needed on perinatal grief, communication skills and help relation techniques. Education is the key that will allow health professionals to manage perinatal loss in a constructive way. ${ }^{[17]}$ In a study involving American obstetricians, it was observed that, in one year, these professionals could delivery care to 12 women having perinatal death. ${ }^{[18]}$

Positive and highly positive attitude regarding perinatal bereavement care were presented in $(26.0 \%$, \& 64.0\%)of the studied participants, these findings are similar to Raddi, Samson, and Kharde, who were reported that, $50.0 \%$ of nurses had a positive attitude towards perinatal bereavement care $^{[12]}$ In addition, Chanwas found that, the majority of nurses in their study held a positive attitude towards be- reavement care. ${ }^{[19]}$

Regarding nurses attitude in relation with their personnel characteristics the present study revealed that, nurses reside in rural areas, had personal grieving experiences and those had past experience in handling grieving parents had a highly positive attitude toward perinatal bereavement care. These findings are in the same line with Moon Fai Chan \& David Gordon Arthur,who pointed out that,there was a significant relation between nurses attitude and their experience in handling grieving parents. ${ }^{[20]}$

In relation to correlation of nurses' knowledge and attitude, the current study was showed that, there was a highly significant correlation between nurses'knowledge and attitude. These results were supported by Chan,who found a positive significant correlation between attitude toward bereavement care and knowledge. ${ }^{[19]}$

These findings are in contradiction with Raddi, Samson, and Kharde who were noticed no significant correlation between knowledge and attitude of nurses regarding bereavement. ${ }^{[12]}$

\section{Conclusion}

This is the first study examining knowledge and attitude of maternity nurse regarding perinatal bereavement care in Egypt, and concluded that, the majority of nurses had inadequate knowledge and $26.0 \%, \& 64.0 \%$ of them had a positive and highly positive attitude regarding bereavement care and $90.0 \%$ of them agreed that they should attach perinatal bereavement training program to enable them to provide care for bereaved parents.

\section{Recommendations}

- Bereavement care should be included in Nursing Schools and Faculties curriculums'.

- Educational programs should be conducted to update nurses' knowledge and enhance their attitude about bereavement care.

- It was advised to conduct the present study on a large sample with different personal characteristics and different geographical areas.

\section{Conflicts of Interest Disclosure}

The authors declare that there is no conflict of interest statement.

\section{References}

[1] Mills TA, Ricklesford C, Cooke A, Heazell AEP, Whitworth M, LavenderT. Parents' experiences and expectations of care in preg- nancy after stillbirth or neonatal death: a metasynthesis. BJOG: An International Journal of Obstetrics \& Gynaecology. 2014.

[2] Cacciatore J. Psychological effects of stillbirth. Seminars in Fetal and Neonatal Medicine. 2013; 18(2): 76-82. http://dx.doi.org $/ 10.1016 / \mathrm{j}$. siny . 
[3] Turton P, Evans C, Hughes P. Long-term psychosocial sequelae of stillbirth: phase II of a nested case-control cohort study. Archives of women's mental health. 2009; 12(1): 35-41. PMid:19137447 http://dx.doi.org/10.1007/s00737-008-0040-7

[4] Harper M, O'Connor RC, O'Carroll RE. Increased mortality in parents bereaved in the first year of their child's life. BMJ supportive \& palliative care. 2011; 1(3): 306-309. PMID:24653475 http://dx.doi.org/10.1136/bmjspcare-2011-000025

[5] Kelley MC, Trinidad SB. Silent loss and the clinical encounter: parents' and physicians' experiences of stillbirth-a qualitative analysis. BMC Pregnancy and Childbirth. 2012. Available from: http: //www. biomedcentral. com/1471-2393/12/137.

[6] Koopmans L, Wilson T, Cacciatore J, Flenady V. Support for mothers, fathers and families after perinatal death. Cochrane database of systematic reviews. 2013. PMID:23784865 http://dx.doi.org /10.1002/14651858. CD000452.pub3

[7] Downe S, Schmidt E, Kingdon C, Heazell AEP. Bereaved parents' experience of stillbirth in UK hospitals: a qualitative interview study. BMJ open. 2013; 3(2).

[8] Saflund K, Sjorgen B, WredlingR. The role of caregiver after childbirth. view and experience of parents. Birth. 2014; 31(2): 132 137. PMID: 15153133 http://dx.doi.org/10.1111/j.0730-7 659.2004.00291.x

[9] Jonas-Simpson C, Pilkington FB, MacDonald C, McMahon E. Nurses' experiences of grieving when there is a perinatal death. SAGE Open. 2013; 3.

[10] Black D, Tufnell G. When is counseling indicated after a major traumatic life event? Current Paediatrics. 2006; 16: 464-471. http://dx.doi.org/10.1016/j.cupe.2006.08.010

[11] Cox E, Briggs S.Disaster nursing: new frontiers for critical care. Critical Care Nurse. 2004; 24(3): 16-22. PMID:15206292

[12] Raddi SA, Samson S, Kharde SN. Knowledge and attitude regarding perinatal bereavement care among nurses working in the maternity unit and neonatal intensive care unit. JSAFOG. 2009; 1(3): 81-84. http://dx.doi.org/10.5005/jp-journals-10006-1017
[13] Zhang W, Lane BS. Promoting neonatal staff nurses' comfort and involvement in end of life and bereavement care. Nursing Research and Practice. 2013. http://dx.doi.org/10.1155/2013/3653 29

[14] Eckerd LM. Death and dying course offerings in psychology: a survey of nine Midwestern states. Death Studies. 2009; 33(8): 762770. PMID:19697486 http://dx.doi.org/10.1080/0748118 0902961211

[15] Chan MF, Lou FI, Zang YL, Chung YF, Wu, LH, Cao FL, et al. Attitudes of midwives towards perinatal bereavement in Hong Kong. Midwifery. 2007; 23: 309-321. PMID:17095131 http://dx.doi .org/10.1016/j.midw. 2006.05.005

[16] Chan MF, Chan SH, Day MC. A pilot study on nurses' attitudes towards perinatal bereavement support: a cluster analysis. Nurse Education.Today. 2004; 24: 202-210. PMID:15046855 http://dx.d oi.org/10.1016/j.nedt.2003.11.009

[17] Montero SM, Sánchez JM, Montoro CH, Crespo ML, Jaén AG, Tirado MB. Experiences with perinatal loss from the health professionals' perspective. Rev. Latino-Am. Enfermagem. 2011; 19(6): 1405-12. http://dx.doi.org/10.1590/S0104-11692011000 600018

[18] Gold KJ, Kuznia AL, Hayward RA. How physicians cope with stillbirth or neonatal death: a national survey of obstetricians. Obstet Gynecol. 2008; 112(1): 29-34. PMID:18591304 http://dx.doi .org/10.1097/A0G.0b013e31817d0582

[19] Chan MF. Investigating factors associate to nurses' attitudes towards perinatal bereavement care. Journal of Clinical Nursing. 2008; 17(4): 509-518. PMID:18205683 http://dx.doi.org/1 $0.1111 / j .1365-2702.2007 .02007 . x$

[20] Chan MF, Arthur DG. Attitudes of nurses toward perinatal bereavement: Findings from a study in Hong Kong.Journal of Perinatal \& Neonatal Nursing. 2005; 19(3): 240-252. http://dx.doi.org/1 $0.1097 / 00005237-200507000-00010$ 